\author{
Scientific Electronic Archives \\ Issue ID: Sci. Elec. Arch. Vol. 15 (2) \\ February 2022 \\ DOI: http://dx.doi.org/10.36560/15220221514 \\ Article link: https://sea.ufr.edu.br/SEA/article/view/1514
}

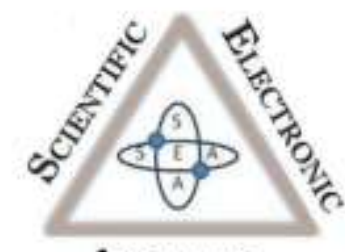

Archives

ISSN 2316-9281

\title{
ADHD: Causes and alternative types of intervention
}

\author{
Aikaterini Doulou \\ N.C.S.R. "Demokritos", Greece \\ Corresponding author \\ Athanasios Drigas \\ N.C.S.R. Demokritos, Greece \\ dr@iit.demokritos.gr
}

\begin{abstract}
In recent years, there has been an increase in the incidence of ADHD in children and adolescents. Many learning and behavioral problems are associated with this disorder as a result of difficulties in cognitive and metacognitive functions. According to Drigas et al. (2021), only when individuals develop these functions can they be integrated in the social environment. Skills such as self-awareness, self-regulation and self-control through inner attention can help children develop alternative strategies to manage their cognitive deficits and adapt in many different environments. With the rapid development of science, several medical and psychological methods have been proposed for the treatment of ADHD, which have contributed significantly to the control of symptoms. In the present work, the causes of ADHD are investigated, as well as alternative forms of intervention that aim to improve the quality of life of these children.
\end{abstract}

Keywords: Attention Deficit Hyperactivity Disorder (ADHD), Social/Emotional Development, Alternative Therapies, ADHD Causes, Metacognition

\section{Introduction}

According to Drigas \& Driga (2019), Attention Deficit Hyperactivity Disorder (ADHD) is a complex neurological disorder that continues to lack scientific data regarding its nature and methods of treatment. Some factors, such as the socioeconomic status of the family, the existence of a psychiatric disorder in the mother, or smoking and alcohol consumption during pregnancy, have been proved to play an important role. Medication is considered to be the first choice of treatment in order to reduce the symptoms, however it has several disadvantages due to the side effects caused and the risk of addiction. Alternative forms of intervention through brain training, on the other hand, seem to be just as effective.

Children with ADHD exhibit difficulties that relate to cognitive and metacognitive functions such as attention retention, self-control and selfregulation. According to Drigas \& Mitsea (2020), some cognitive functions such as attention seem to surpass others, as they function simultaneously as cognitive and metacognitive abilities. Researchers distinguish between external and internal attention. External attention focuses on selecting and processing data from the senses, while internal attention involves the cognitive control of information already stored in the brain, recalled from the longterm memory or retained in the working memory (Chun et al., 2011).

In order to control the symptoms of ADHD, training that focuses on the development of cognitive and metacognitive skills is required. According to Drigas et al. (2021), cognitive and metacognitive skills evolve progressively, depending on practicing individual activities related to self-awareness of strengths and weaknesses through experience, to self-observation through various techniques that enhance attention, to self-regulation, adaptation and flexibility in various areas (cognitive, emotional, behavioral), to recognition, to discrimination and to mindfulness. Only when individuals develop these pillars of metacognition will they be able to incorporate the appropriate cognitive and socioemotional skills that will enable them to integrate in the social environment. Metacognition is the most valuable tool in self-learning, self-development and self-healing. It should therefore be the cornerstone of a special intervention program that promotes holistic learning. 


\section{Causes}

The etiology of ADHD has not yet been precisely determined, however in recent years many studies have attempted to explain its nature. Several factors seem to be responsible, such as genetic, neurobiological, environmental, or even psychosocial. However, according to most research data, it is argued that the most important factors are neurobiological and genetic (Barkley, 2003).

\section{Genetic factors}

It is argued that hereditary predisposition to ADHD is an important factor in the disorder. It has been observed that 50 percent of children whose parents have been diagnosed with ADHD are more likely to develop the disorder, while there is a high risk of 33 percent among siblings (Barkley, 2003; Kring \& Johnson 2019). According to Tannock (1998), ADHD is due to genetic factors by heredity that can reach 70 to 80 percent as shown by a multitude of studies, which used the method of twins and the method of adoption. Research on monozygotic twins has shown that siblings of hyperactive children often have the same hyperactivity. Dizygotic twins (DZ) on the other hand, exhibit less symptoms in common (Barkley, 2003). These studies demonstrate the minimal impact of the environment on the occurrence of the disorder. Furthermore, it has been observed that parents as well as other relatives of children with ADHD, often exhibit emotional disorders, behavioral problems and substance abuse (Kring \& Johnson 2019).

In terms of molecular genetics, ongoing research is being carried out with the ultimate goal of identifying the genes involved in ADHD. More specifically, the studies focus on two different dopamine-related genes, the dopaminergic receptor DRD4 gene and the dopamine transporter DAT1 gene (Kring et.al, 2010).

\section{Neurobiological factors}

Many studies conducted during the 20th century have found similarities between people with ADHD and people with brain damage due to brain infections or frontal lobe injuries. As a result, researchers have linked the disorder to neurobiological causes (Barkley, 2003). Later, using magnetic resonance imaging in children with $A D H D$, differences were found in the frontal lobe and the left temporal lobe of the brain (Biederman, 2000). Specifically, cognitive difficulties in attention retention, emotional self-regulation, working memory and behavioral organization are due to damage in the frontal lobe of the cerebral cortex, while difficulties in auditory distinction and analysis are due to the temporal lobes. (Grattan \& Eslinger, 1991; Sieg et al., 1995).

It has been observed that blood flow to the brain of children with ADHD is significantly lower (Sieg et. Al., 1995). Also, according to research by Zametkin (1990) performed with the PET method (positron emission tomography), adults with ADHD showed decreased glucose metabolic activity. It is also important to note that the neuroimaging methods used in the research, did not detect any structural brain damage. However, it was observed that areas of the brain associated with ADHD, such as the prefrontal cortex and basal ganglia, were smaller than those of children who did not have ADHD (Barkley, 2003).

\section{Environmental factors}

The causes of ADHD can be prenatal, perinatal or postnatal. Many studies suggest that nicotine is a toxic substance and that children born to pregnant smokers are more likely to develop ADHD. According to a study by Milberger (1996), 22 percent of children who were diagnosed with ADHD had mothers who smoked on a daily basis large amounts of cigarettes while pregnant. Therefore, the exposure of a fetus to tobacco can be a predictor of the onset of ADHD symptoms. Animal studies have suggested that increased dopamine release due to nicotine consumption may cause hyperactivity, while decreased dopamine release due to nicotine deprivation may cause irritability (Vaglenova et al., 2004). Exposure of the fetus to toxic substances also includes alcohol and lead. In the case of lead, it may be associated with symptoms of attention deficit hyperactivity disorder (Thompson et al., 1989).

Nutritional factors are equally important. Additives and dyes contained in some foods can stimulate the central nervous system of children with ADHD, while others argue that even simple foods such as corn, milk, eggs and sugar can cause sensitivity (McCann et al. 2007). Also, Grizenko et al. (2008), conducted research through interviews with questions concerning the psycho-emotional state of mothers during pregnancy, whose children were diagnosed with ADHD. According to their conclusions, they argue that the stronger the stress a mother experiences during pregnancy, the more serious will the ADHD symptoms be that those children may develop.

\section{Psychosocial factors}

The prevailing view around the etiology of ADHD considers genetic and neurobiological factors as the most important. However, several studies have focused on psychosocial factors and the extent to which they affect the onset of symptoms. The findings suggest that psychological factors can not cause the disorder, however they have the potential to contribute to the intensity of its symptoms (Barkley, 2003; Kring \& Johnson 2019). The quality of the relationship that children with ADHD develop with their parents, especially with their mother, has a reciprocal effect on genetic and neurobiological factors (Hinshaw, 1997). Most often, their parents relate to them in a negative way due to their difficulty in handling their children's symptoms, which in turn results in difficult behavior of the children (Kring et al., 2010). Research by Arnold et al. (1997) found that fathers of children with ADHD who had also 
been diagnosed with the disorder themselves were ineffective in their children's upbringing, ergo suggesting that parental psychopathological disorder may directly affect the outcome of ADHD symptoms in their children.

Dysfunctional parental behaviors towards children with ADHD, such as psychological deprivation or strict control, can cause conflicts that may result in children becoming less compliant or even developing consequential problems in addition to ADHD. Finally, the social characteristics of the family, such as the parents' educational and economic level, their social class or profession can affect the symptoms of ADHD from 0 to 6 percent (Barkley, 2003; Kring \& Johnson 2019).

\section{Alternative types of intervention}

Lange studies in his literature research (2020) the need of using alternative therapies in children with ADHD. Methylphenidate is the first drug to be approved for the treatment of symptoms of hyperactivity or attention deficit in children and adults, but concerns about its possible side effects have led to searching for alternative therapies. The purpose of this study is to present the extent to which lifestyle factors, such as the quality of nutrition, exercise, quality of sleep and proper use of electronic media can improve the symptoms of the disorder.

Questions about whether vitamin deficiencies are related to ADHD and whether vitamin supplements have therapeutic effects remain still open. The main nutrients that seem to be useful in the treatment of ADHD include micronutrients such as minerals and vitamins, and polyunsaturated fatty acids. Several studies have shown reduced blood plasma levels of various minerals, such as magnesium, iron and zinc in children with ADHD, and their supplementation may reduce symptoms. However, there is a lack of evidence to support this (Lange, 2017). A recent study by Blazynski (2020) evaluated the effects of an oligoantigenic diet, by eliminating certain foods and reintroducing specific nutrients for four weeks in children with ADHD. A response rate of about 60 percent was observed, with significant positive effects on attention and behavior.

In terms of exercise, the findings of a metaanalysis suggest that short-term aerobic exercise (over 6-10 weeks) had a moderate to large effect on ADHD symptoms, as well as other comorbid symptoms, such as anxiety and social difficulties (Cerilo-Urbina et al., 2015). Similarly, data from another review of long-term aerobic physical activity suggest that physical activity may be beneficial for ADHD symptoms and motor skills (Hoza et al., 2016). A systematic review of 30 short- and longterm studies underlined the clinical benefits of physical exercise in behavioral and cognitive deficits in children with ADHD ( $\mathrm{Ng}$ et al., 2017). Regarding sleep schedules, a study by Cao et al. (2018), with a sample of 15,291 preschool children in China, showed that delayed sleep time was closely associated with the risk of developing ADHD symptoms, while longer sleep times (> 8.5 hours) were associated with a reduced risk of developing ADHD symptoms. When it comes to using electronic media, children with ADHD can be particularly vulnerable to overuse. This includes electronic games, as they require relatively little attention and offer immediate rewards. The results of a metaanalysis showed a small but significant relationship between an increased use of electronic media and ADHD symptoms (Nikkelen et al., 2014).

Based on all of the above, Lange (2020) concludes that people with ADHD can benefit from improved lifestyle choices. The role of individual micronutrients and macronutrients, such as minerals, vitamins and polyunsaturated fatty acids, remains unclear in the treatment of ADHD. Also, physical exercise can be a promising alternative treatment, while the relationship between ADHD, insomnia and electronic media requires further research.

The research of Barzegary and Zamini (2011) studied the effects of play therapy in children with ADHD. Numerous studies have shown that play therapy is an ideal method for the emotional and social problems of children with ADHD (Braton, 2005), while another study suggests that play therapy enhances the control of their impulsivity (Pankespp, 2007). The purpose of this research is to study whether play therapy increases the attention of children with ADHD and whether it reduces their hyperactivity. For this purpose, 14 children with ADHD were selected and randomly assigned to two groups (control group and experimental group). The research tool used was the Children Symptoms Inventory-4 (CSI-4), which is an assessment scale referred to in the DSM-IV that monitors the emotional and behavioral symptoms of childhood disorders. There is the version for parents and the version for teachers. Initially, parents were interviewed and afterwards they completed the test. All children were 7 to 8 years old and attended play therapy in ten sessions (three per week). The goal was to pay full attention to an activity (for example, painting) until they heard a bell ringing. With each distraction they would lose a token (Barzegary and Zamini, 2011).

According to results, the levels of attention deficit and hyperactivity were lower in the experimental group, suggesting that play therapy may improve the symptoms of the disorder. There is also a significant difference between the control group and the experimental group regarding their hyperactivity and attention deficit scores. Ergo, the conclusions that emerge show that after the intervention with the play sessions, there was a reduction of ADHD symptoms, confirming the hypotheses of this research, as also do the results of other research on the effectiveness of play therapy (Barzegary \& Zamini, 2011). Some studies have shown that when children participate in play 
sessions, they feel very happy and these emotions lead to great attention and accuracy in different activities. Play therapy also helps them spend some of their energy. This energy expenditure leads to a reduction in their impulsivity and hyperactivity during the rest of the day (Ray et al, 2008).

The research of Samantha, Cohen, Danielle, Harvey, Rebecca, Shields, et al. (2018), studied the effects of yoga on attention, impulsivity, and hyperactivity in preschool children with ADHD. Yoga is a form of meditation and physical exercise, which incorporates physical postures and breathing exercises in order to develop self-regulatory skills (Gard et al., 2014). Previous studies evaluating the effects of yoga on school-age children with ADHD have shown promising results, as an improvement in attention during activities was observed (Peck et al., 2005). Also, parents who practiced yoga with their children reported better management of their stress and improved parent-child relationships (Harrison, 2004). The aims of the research were to evaluate the effect of yoga on ADHD symptoms, as well as the preservation of the intervention's impact over time. The researchers hypothesized that engaging in yoga for 6 weeks would lead to improvements in ADHD symptoms.

The study involved 23 children aged 3 to 5 years with 4 or more ADHD symptoms, who were divided into two groups. These children were at high risk for ADHD, but a diagnosis was not necessary, as ADHD often cannot be diagnosed in preschool children. A controlled 6 -week yoga intervention was performed at home and at school. Behavioral symptoms were assessed using 2 parent-teacher scores: ADHD RS-IV Preschool Version (McGoey et al., 2007) and Strengths and Difficulties Questionnaire (SDQ) (Bourdon et al., 2005). Attention was measured via computer-based activities using the Kinder Test of Attentional Performance (KiTAP, 2002). Heart rate variability (HRV) was also assessed as a normal indicator of self-regulation. Qualitative data were also collected after each intervention through questionnaires and interviews with parents, teachers and yoga instructors. To maximize the frequency of yoga, the intervention was performed at home and at school. During the first 6 weeks, students in Group 1 practiced school yoga in a separate room other than their classroom and concluded yoga at home with parental encouragement using a yoga DVD. Group 2 , continued with activities as usual in the classroom and at home, without any exposure to yoga (Samantha et al., 2018).

The results showed that there were improvements in the parental assessment scales for Group 1 children; many parents were satisfied with the behavioral changes they observed after yoga and felt that this training helped their children learn self-calming skills. The parents' overall satisfaction with the program was very promising and most of them would recommend this program to others. In both groups, most parents did not notice any changes in their children's appetite, sleep patterns, moods, stress levels or parent-child relationships, but they did notice changes in their children's attention span. It is important to note however, that the teachers' scores for inattention symptoms did not improve significantly after the yoga practice, which may be due to the fact that teachers try to manage an entire busy classroom and thus are less likely to notice these symptoms. Also, the results of the Kinder Test of Attentional Performance (KiTAP) revealed that children in Group 1 showed an improved ability for attention and significantly better response times to correct answers, but unexpectedly showed also a higher impulsivity after yoga (Samantha et al., 2018).

The literature research by Cerrillo-Urbina, Garsia-Hermoso, Sanchez-Lopez, Pardo-Guijarro, Gomez \& Martinez-Vizcaino (2015) studied the effects of physical exercise on children with ADHD. Numerous studies suggest that physical exercise affects the same catecholaminergic systems as medications for ADHD do, and may therefore be effective in managing symptoms (Tomporowski et al. 2008; Wigal et al. 2013). For this purpose, research was conducted among five databases covering the period up to November 2014 (PubMed, Scopus, EMBASE, EBSCO [E-journal, CINAHL and SportDiscus] and The Cochrane Library). Search criteria included studies concerning children or adolescents aged 6-18 years, who had been diagnosed with $A D H D$ and were receiving regular medication, while no criteria were applied regarding frequency or duration of training. The analysis of data was performed via Review Manager (Update Software, Oxford) (Thalheimer 2014) using the Glass method (Egger et al. 1997). After a literature review, eight research studies were analyzed and categorized based on the type of intervention, i.e. in aerobic exercises and yoga therapies. Overall research included 249 children who had been diagnosed with ADHD. Of these, 230 participated in aerobic exercise and 19 in yoga exercise. Seven studies evaluated the effect of aerobic exercise on children with ADHD (Tantillo et al. 2002; Mackune et al. 2003; Kang et al. 2011; Chang et al. 2012; Verret et al. 2012; Pontifex et al. 2013; Choi et al. 2015) and only one the effects of yoga (Jensen \& Kenny 2004).

Overall, the research findings show that aerobic exercise seems to reduce among other symptoms inattention, impulsivity, or hyperactivity in children with ADHD. Data on the benefits of yoga were scarce due to the small number of articles retrieved. Exercise is likely to be beneficial for children with ADHD due to changes in dopamine levels and its release (Wigal et al. 2003; Chang et al. 2012). Thus, the release of dopamine during exercise therapy helps improving the symptoms of inattention (Kang et al. 2011). According to the study, it was observed that sport (Verret et al. 2012; Choi et al. 2015) and especially running leads to excellent improvements regarding ADHD symptoms 
(Mackune et al. 2003; Kang et al. 2011; Choi et al. al. 2015). Also, the findings in this meta-analysis showed a decrease in impulsivity through physical exercise (Kang et al. 2011; Verret et al. 2012). Exercise can also reduce the response time in activities that require a greater working memory capacity (Pontifex et al. 2009) and reduce inattention (Mackune et al. 2003; Kang et al. 2011; Verret et al. 2012; Pontifex et al. 2013). Therefore, it is observed that there is an obvious improvement in cognitive function (Kang et al. 2011; Verret et al. 2012). With regard to yoga, the results included in the metaanalysis revealed substantial improvements such as reduced impulsivity, stress and social problems, and improved attention and hyperactivity (Jensen \& Kenny 2004).

The research of Santonastaso, Zaccari, Crescentini, Fabbro, Capurso, Vicari, et al. (2020), studied the effects of meditation and mindfulness on children with ADHD. Meditation is a promising selfregulatory training method used for attention and behavior problems, which has started to gain support as a complementary or alternative intervention for ADHD (Cairncross \& Miller, 2016). A fundamental mechanism of meditation is the regulation of attention, which comes from practicing in recognizing the thoughts, feelings, and sensations of the body and the effort to re-focus on the self, when one realizes that his/her concentration has been distracted (Malinowski, 2013).

For the purpose of the research, 32 children with ADHD aged 7-11 years were randomly divided into two groups, the MOM group (Meditation and Mindfulness Training Program) and the EEP group (Emotional Education Program). After training, the participants were assessed via neuropsychological measurements that included aspects such as working memory, inhibitory control, ADHD symptoms, behavioral and emotional aspects, symptoms of depression and anxiety, and school learning skills such as mathematical calculations and reading. None of the children had received any pharmacological, psychological, behavioral or alternative therapy (Santonastaso et al., 2020). The MOM program (meditation training) was implemented with children and consisted of 3 weekly sessions for 8 weeks. With regard to previous meditation programs, the duration of the sessions gradually increased over time, starting at 6 minutes and increasing up to 30 minutes (Flook et al., 2010). Each session was divided into a series of three meditation exercises focusing on three types of activity: (1) attention to breathing, (2) attention to parts of the body, and (3) attention to thoughts and emotions. The EEP program (emotion training) was designed to be comparable and structurally equivalent to the MOM program. It was conducted too in 3 sessions per week, for 8 weeks and the duration of the sessions followed the same progress as the MOM training. During EEP training, children were encouraged to listen to and comment on chapters of a book in order to discover and experience different emotions (Santonastaso et al., 2020). The researchers of the present study predicted that MOM training would have positive results in neuropsychological trials related to executive functions. They also predicted that, according to parental feedback scores, there would be greater improvements regarding attention ability and ADHD symptoms in MOM versus EEP trainings (Santonastaso et al., 2020).

Upon completion of the interventions, the children of both groups were evaluated with CPT-II V.5. (Conners' Continuous Performance Test-II 5th Version) (Conners, 2004), which calculated reaction times with the push of a button; children had to press the space bar on a computer each time a letter appeared on the screen except for the letter "X". The Stroop Color-Word Test was also performed, where children had to read words and name colors as quickly and accurately as possible (Golden \& Freshwater, 2002). In addition, assessment questionnaires were given to the parents such as the Conners' Parent Rating Scales Long Version Revised (CPRS-R: L) (Conners, 1997 that comprises of behavioral assessment scales related to ADHD and other children disorders, the Multidimensional Anxiety Scale for Children (MASC) (March et al., 1997), the Children's Depression Inventory (CDI) (Kovacs, 1982), and the Development and Validation of the Child and Adolescent Mindfulness Measure (CAMM) (Greco et al. al., 2011), which detects the level of mindfulness in children and adolescents.

The results showed that according to parents' scores ADHD symptoms were reduced in several subcategories of CPRS-R: L. after MOM trainings. There was also a significant improvement in all neuropsychological trials after MOM training, which could significantly reduce the difficulties of executive functions due to ADHD. Positive results of the impact of meditation were also observed in the working memory, a fact that verified the immediate relationship between attention and executive functions. In conclusion, mindfulness-oriented interventions have a major impact on reducing the fundamental symptoms of ADHD, as during meditation participants' attention is focused on present experiences, thus improving self-regulation (Santonastaso et al., 2020).

Dawson \& Persad (2021) elaborate in their article on alternative methods for increasing anandamide levels, as a therapeutic intervention in children with ADHD. The endocannabinoid system has been identified in various dopamine deficiency disorders including ADHD. The endocannabinoid that is responsible for the release of dopamine is anandamide and increasing the concentrations of this molecule has therapeutic value for ADHD (Giuffrida et al., 1999). Usually, either amphetamine (Adderall) or methylphenidates (Ritalin) are at the forefront of pharmacotherapy for ADHD. These drugs stimulate the release of dopamine, which is low in children with ADHD, but unfortunately they 
are addictive and lead to a number of unpleasant side effects, such as gastrointestinal problems, pituitary dysfunction, blood pressure problems, anxiety, headaches, developmental delay and nausea (Shier et al., 2012). The purpose of this article is to study more natural ways that contribute to the release of dopamine.

Studies have shown that the phytocannabinoids $\mathrm{CBC}, \mathrm{CBN}, \mathrm{THC}$ and $\mathrm{CBG}$ activate the anandamide receptors, thus increasing dopamine concentrations, while CBD releases serotonin all of which helps with the symptoms of ADHD (Schier et al., 2014). The effectiveness of phytocannabinoid supplementation in the treatment of endocannabinoid deficiency disorders is known and accepted by science. However, the use of this knowledge is still in its infancy (Hill et al., 2018). Nutraceuticals have the advantage of being natural and offering some biomolecular effect. But because they are natural they have the disadvantage that they cannot be considered for approval by the FDA (Santini et al., 2018). Furthermore, there is limited data regarding the safety profiles of phytocannabinoids for both adults and children, ergo it is important to conduct more research (Dawson \& Persad, 2021).

\section{Conclusion}

Children with ADHD exhibit a range of symptoms, with the main features of the disorder being inattention, hyperactivity and impulsivity. To be able to control these symptoms it is necessary to exercise cognitive and metacognitive skills. According to Drigas \& Mitsea (2021), metacognition is one of the most important success factors in the 21 st century and refers to a set of superior abilities, skills and self-regulation strategies. The basic metacognitive functions are considered to be multidimensional and in no way one-dimensional. The same also goes for cognitive skills such as attention, memory, perception and language. Rising from lower to higher levels of metacognition results in transitioning to advanced forms of self-awareness. Specifically, metacognition is the ability to selfcontrol, self-regulate and to adapt thoughts, feelings and behaviors, as well as to recognize and distinguish between functional and dysfunctional mental or emotional states, so that one is aware of the full range of their strengths. Self-control is at the heart of metacognition that is achieved only when one reaches the conscious awareness of their physical, spiritual and emotional potential (Drigas \& Mitsea, 2021).

Alternative interventions to treat ADHD seem to be gaining more and more support from the scientific community over time. Due to the observed side effects as a result of medication, alternative interventions are suggested by researchers as more natural ways to manage and improve ADHD symptoms. Interventions, based on mindfulness and meditation, have a significant impact on reducing the primary symptoms of ADHD, as well as on the ability for self-regulation. It is also argued that people with ADHD can benefit from improved lifestyle choices by incorporating qualitative diet and sleep schedules in their daily routine. Exercise, too, can be a promising alternative treatment for managing symptoms; it can replace medication, since it has the same effect as stimulants for ADHD. Samantha et al. (2018) studied the effects of yoga on preschool children with ADHD and observed improvements in parents' assessment scores on attention, impulsivity and hyperactivity. However, the role of yoga in the treatment of ADHD remains unclear and is subject to further research. Finally, play therapy is a proposed alternative method of intervention, as lower levels of attention deficit and hyperactivity are observed in children with ADHD after treatment.

The discussion around the causes of ADHD and corresponding rehabilitation methods is a reflection of the fluidity of our knowledge in these areas. Further research is needed to identify the causes of this disorder and to develop alternative therapies with the aim of improving the cognitive and metacognitive skills of these children and enabling them to integrate in the social environment.

\section{References}

Arnold, E. M., Elliot M., Sachs L., et al. (1997). Father involvement and self-reported parenting of children with attention-deficit hyperactivity disorder. Journal of Consulting and Clinical Psychology, 65, 337-342.

Barkley, R. A. (2003). Attention-deficit/hyperactivity disorder. In E. J. Mash \& R. A. Barkley (Eds.), Child psychopathology (p. 75-143). Guilford Press.

Barzegary, L. \& Zamini, S. (2011). The effect of play therapy on children with ADHD. Procedia-Social and Behavioral Sciences 30, 2216-2218.

Biederman, J., Faraone, S. V. \& Monuteau, M. C. (2000). Differential effect of environmental adversity by gender. Rutter' $s$ index of adversity in a group of boys and girls with and without ADHD. Am J. Psychiatry 159, 1556-1562.

Blazynski, N., Schneider-Momm, K., Overdick, L., et al. (under review). Oligoantigenic diet in children with ADHD. Front Psychiatry.

Bourdon, K.H., Goodman, R, Rae, D.S., et al. (2005). The strengths and difficulties questionnaire: U.S. normative data and psychometric properties. $J$ Am Acad Child Adolesc Psychiatry, 44:557-564.

Bratton, S., Ray, D., Rhine, T., \& Jones, L. (2005). The efficacy of play therapy with children: A Metaanalytic review of the outcome research. Professional Psychology: Research and Practice, 36(4), 376-390. 
Cairncross, M. \& Miller, C.J., (2016). The effectiveness of mindfulness-based therapies for ADHD: A meta-analytic review. J. Atten. Disord., 20, $1-17$.

Cao, H., Yan, S., Gu, C., et al. (2018). Prevalence of attention-deficit/hyperactivity disorder symptoms and their associations with sleep schedules and sleeprelated problems among preschoolers in mainland China. BMC Pediatr., 18: 70.

Cerrillo-Urbina, A. J., García-Hermoso, A., Sánchez López, M., Pardo-Guijarro, M.J., Santos-Gómez, . L, Martínez-Vizcaíno, V., (2015). The effects c physical exercise in children with attention-defic. hyperactivity disorder: a systematic review an. meta-analysis of randomized control trials. Chil Care Health, 41: 779-788.

Cerrillo-Urbina, A. J., García-Hermoso, A., Sánchez López, M., Pardo-Guijarro, M.J., Santos-Gómez, _. L, Martínez-Vizcaíno, V., (2015). The effects c physical exercise in children with attention-defic hyperactivity disorder: a systematic review an meta-analysis of randomized control trials. Chil Care Health, 41: 779-788.

Chang, Y. K., Liu, S., Yu, H. H. \& Lee, Y.H., (2012). Effect of acute exercise on executive function in children with attention-deficit hyperactivity disorder. Archives of Clinical Neuropsychology, 27, 225 -237. Choi, J. W., Han, D. H., Kang, K. D., Jung, H. Y. \& Renshaw, P. F. (2015). Aerobic exercise and attention-deficit hyperactivity disorder: brain research. Medicine and Science in Sports and Exercise, 47, 33 -39.

Chun, M. M., Golomb, J. D., \& Turk-Browne, N. B. (2011). A taxonomy of external and internal attention. Annual review of psychology, 62, 73-101.

Conners, C.K. \& MHS, Staff. (2004). Conners' Continuous Performance Test-II 5th Version (CPT-II V.5). Technical Guide and Software Manual. Multi Health System: North Tonawanda, NY, USA.

Conners, C.K. (1997). Conners' Rating ScalesRevised (Italian adaptation). Giunti, O.S., Ed. Organizzazioni Speciali: Firenze, Italy.

Dawson, D. A. \& Persad, C. P., (2021). Targeting the Endocannabinoid System in the Treatment of ADHD. Genet Mol Med., 3(1): 1-7.

Drigas, A.S., Driga, M. A. (2019). ADHD in the Early Years: Pre-Natal and Early Causes and Alternative Ways of Dealing. International Journal of Emerging Technologies in Learning (iJET). 15(13):95-102, 2019. DOI: $10.3991 /$ ijoe.v15i13.11203

Drigas, A.S., Mitsea, E. (2020). The 8 Pillars of Metacognition. International Journal of Emerging
Technologies in Learning (iJET). Vol.15, n.21, p.162-178. DOI: $\underline{10.3991 / i j e t . v 15 i 21.14907}$

Drigas A. S., Mitsea E., Mantas P. (2021). Soft Skills \& Metacognition as Inclusion Amplifiers in the 21st Century. International Journal of Online and Biomedical Engineering (iJOE). 17(4):121-132. DOI: $10.3991 /$ ijoe.v17i04.20567

- Drigas A. S. \& Mitsea E. (2021). Metacognition, Stress - Relaxation Balance \& Related Hormones. International Journal of Recent Contributions from Engineering Science \& IT (iJES), 9(1):4-15. DOI: $\underline{10.3991 / i j e s . v 9 i 1.19623}$

Drigas A. S. \& Mitsea E. (2021). 8 Pillars X 8 Layers Model of Metacognition Educational Strategies, Exercises \&Trainings. International Journal of Online and Biomedical Engineering (iJOE), 17(8):115-134. DOI: $10.3991 /$ ijoe.v17i08.23563

Egger, M., Davey Smith, G., Schneider, M. \& Minder, C. (1997) Bias in meta-analysis detected by a simple graphical test. BMJ,315:629-634.

Flook, L., Smalley, S.L., Kitil, M.J., Galla, B.M., Kaiser-Greenland, S., Locke, J. et al. (2010). Effects of mindful awareness practices on executive functions in elementary school children. J. Appl. Sch. Psychol., 26, 70-95.

Gard, T., Noggle, J.J., Park, C.L. et al. (2014). Potential self-regulatory mechanisms of yoga for psychological health. Front Hum Neurosci., 8:770.

Giuffrida, A., Parsons, L.H., Kerr, T.M., et al. (1999). Dopamine activation of endogenous cannabinoid signaling in dorsal striatum. Nature Neuroscience, 2: 358.

Golden, C.J., Freshwater, S.M. (2002). The Stroop Color and Word Test: A Manual for Clinical and Experimental Uses. Stoelting: Chicago, IL, USA.

Grattan, M., \& Eslinger, J. (1991). Frontal lobe damage in children and adults: A comparative review. Developmental neuropsychology, 7, 283326.

Greco, L.A., Baer, R.A., Smith, G.T. (2011). Assessing mindfulness in children and adolescents: Development and validation of the child and adolescent mindfulness measure (CAMM). Psychol. Assess., 23, 606-614.

Grizenko, Shayan, Polotskaia, Ter-Stepanian, Joober (2008). Relation of maternal stress during pregnancy to symptom severity and response to treatment in children with ADHD. Journal of Psychiatry and Neuroscience. 33(1), 10-16.

Harrison, L. J. (2004). Sahaja yoga meditation as a family treatment programme for children with 
attention-deficit/hyperactivity disorder. Clin. Child Psychol. Psychiatry, 9: 479-497.

Hill, M.N., Campolongo, P., Yehuda R., et al. (2018). Integrating endocannabinoid signaling and cannabinoids into the biology and treatment of posttraumatic stress disorder. Neuro psychopharmacology, 43: 80-102.

Hinshaw, S. P., Zupan, B. A., Simmel, C., Nigg, J. T. \& Melnick S. (1997). Peer status in boys with and without Attention-Deficit Hyperactivity Disorder: Predictions from overt and covert anti-social behavior, social isolation and authoritative parenting beliefs. Child Development, 68, 880-896.

Hoza, B., Martin, C.P., Pirog, A., Shoulberg, E.K. (2016). Using physical activity to manage ADHD symptoms: the state of the evidence. Curr. Psychiatry Rep. 18: 113.

Jensen, P. S. \& Kenny, D. T. (2004). The effects of yoga on the attention and behavior of boys with attention-deficit/hyperactivity disorder (ADHD). Journal of Attention Disorders, 7, 205-216.

Kang, K. D., Choi, J. W., Kang, S. G. \& Han, D. H. (2011). Sports therapy for attention, cognitions and sociality. International Journal of Sports Medicine, 32, 953-959.

Kerig. P. K., Ludlow A. \& Wenar, C. (2012). Developmental Psychopathology: From Infancy to Adolescence. New York: McGraw-Hill Education.

Kring, A. M. \& Johnson, S. L. (2019). Abnormal Psychology: The Science and Treatment of Psychological Disorders. New York: John Wiley \& Sons.

Lange, K. W., (2020). The need for alternative treatments for attention-deficit/hyperactivity disorder. Movement and Nutrition in Health and Disease, 4: 1 9.

Mackune, A., Puatz, J., Lombard, J. (2003). Behavioural response to exercise in children with attention-deficit/hyperactivity disorder. SA Sports Medicine, 15, $17-21$.

Malinowski, P. (2013). Neural mechanisms of attentional control in mindfulness meditation. Neuroscience, 7 (8).

March, J.S., Parker, J. D. A., Sullivan, K., Stallings, P., Conners, C. K. (1997). The Multidimensional Anxiety Scale for Children (MASC): Factor structure, reliability, and validity. J. Am. Acad. Child Adolesc. Psychiatry, 36, 554-565.

McCann, D., Barrett, A., Cooper, A., Crumbler, D., Dalen, L., Grimshaw, K., et al. (2007). Food additives and hyperactive behavior in 3-year-old and 8/9-year-old children in a community: a randomized, double blinded, placebo controlled trial. Lancet, 370, 1560-1567.

McGoey, K.E., DuPaul, G.J., Haley, E., et al. (2007). Parent and teacher ratings of attention/deficit/hyperactivity disorder in preschool: the ADHD rating scale-IV preschool version. J Psychopathology Behav Assess., 29:269-276.

Milmberger, S., Biederman, J., Faraone, S. V., \& Chen, L. (1996). Is maternal smoking, during pregnancy a risk factor for attention deficit hyperactivity disorder in children? American Journal of Psychiatry, 153, 1138-1142.

Ng, Q.X., Ho, C.Y.X., Chan, H.W., Yong, B.Z.J., Yeo, W.S. (2017). Managing childhood and adolescent attention-deficit/hyperactivity disorder (ADHD) with exercise: a systematic review. Complement Ther. Med., 34: 123-128.

Nikkelen, S.W., Valkenburg, P.M., Huizinga, M., Bushman, B.J. (2014). Media use and ADHD-related behaviors in children and adolescents: a metaanalysis. Dev. Psychol., 50: 2228-2241.

Panksepp, J. (2007). Can play diminish ADHD and facilitate the construction of the social brain? J. Acad. child Adolescent Psychiatry, 16: 20.

Peck, H.L., Kehle, T.J., Bray, M.A., et al. (2005). Yoga as an intervention for children with attention problems. Sch. Psychol. Rev. 34:415.

Pontifex, M. B., Hillman, C. H., Fernhall, B., Thompson, K. M. \& Valentini, T. A. (2009). The effect of acute aerobic and resistance exercise on working memory. Medicine and Science in Sports and Exercise, 41, 927-934.

Ray, D., Bratton, S., Rhine, T., Jones, L. (2008). The effectiveness of play therapy: Responding to the critics. International Journal of Play Therapy: 10, 85- 108.

Samantha, C. L., Cohen, Danielle, J., Harvey, Rebecca, H., Shields et al. (2018). Effects of Yoga on Attention, Impulsivity and Hyperactivity in Preschool-Aged Children with Attention-Deficit Hyperactivity Disorder Symptoms. Journal of Developmental \& Behavioral Pediatrics, Vol. 39, No. 3, 200-209.

Santini, A., Cammarata, S.M., Capone, G., et al. (2018). Nutraceuticals: opening the debate for a regulatory framework. British journal of clinical pharmacology, 84: 659-672.

Santonastaso, O., Zaccari, V., Crescentini, C., Fabbro, F., Capurso, V., Vicari et al. (2020). Clinical Application of Mindfulness-Oriented Meditation: A 
Preliminary Study in Children with ADHD. International Journal of Environmental Research and Public Health, 17, 6916.

Shier, A.C., Reichenbacher, T., Ghuman, H.S., et al. (2012). Pharmacological treatment of attention deficit hyper activity disorder in children and adolescents: clinical strategies. Journal of central nervous system disease, 5: 1-17.

Sieg, K. G., Gaffney, G. R., Preston, D. F. \& Hellings, J. A. (1995). SPECT brain imaging abnormalities in attention deficit hyperactivity disorder. Clinical Nuclear Medicine, 20, 55-60.

Tannock, R. (1998). Attention-deficit hyperactivity disorder. Advances in cognitive, neurobiological and genetic research. Journal of Child Psychology and Psychiatry, 39, 65-100.

Tantillo, M., Kesick, C. M., Hynd, G. W. \& Dishman, R. K. (2002). The effects of exercise on children with attention-deficit hyperactivity disorder. Medicine and Science in Sports and Exercise, 34, 203 -212.

Thalheimer, W, C. S. (2014) How to calculate effect sizes from published research: a simplified methodology. http://work-learning. com/effect_sizes.html (accessed 15 October 2014).

Thompson, G. O. B., Raab, G. M., Hepburn, W. S., Hunter, R., Fulton, M., \& Laxen D. P. H. (1989). Blood-lead levels and children's behavior: Results from the Edinburgh lead study. Journal of Child Psychology and Psychiatry, 30, 515-528.

Tomporowski, P. D., Davis, C. L., Miller, P. H. \& Naglieri, J. A. (2008) Exercise and children's intelligence, cognition, and academic achievement. Educational Psychology Review, 20, 111-131.

Vaglenova, J., Birru, S., Pandiella, N. M., \& Breese, C. R. (2004). An assessment of the long term developmental and behavioral teratogenicity, of prenatal nicotine exposure. Behavioral Brain Research, 150, 159-170.

Verret, C., Guay, M. C., Berthiaume, C., Gardiner, P. \& Beliveau, L. (2012) A physical activity program improves behavior and cognitive functions in children with ADHD: an exploratory study. Journal of Attention Disorders, 16, $71-80$.

Wigal, S. B., Emmerson, N., Gehricke, J. G. \& Galassetti, P. (2013) Exercise: applications to childhood ADHD. Journal of Attention Disorders, 17, 279-290.

Zametkin, A. J., Nordahl, T. E., Gross, M., King, A. C., Semple, W. E., Rumsey, J. et al. (1990). Cerebral glucose metabolism in adults with hyperactivity of childhood onset. New England Journal of Medicine, 323, 1361-1366. 